\title{
Monográfico: Educación Musical y Medios Audiovisuales
}

\author{
Monographic: Music Education and Audio-Visual Media
}

\author{
Juan Carlos Montoya Rubio \\ juancarlos.montoya@um.es \\ Departamento Didáctica de la Expresión Plástica, Musical y Dinámica \\ Universidad de Murcia \\ Murcia, España \\ ORCID: 0000-0002-1697-0023
}

La aparición del presente número monográfico en torno a los medios audiovisuales y su aplicación didáctica supone un paso más en el reconocimiento de unos recursos pedagógicos que, por un lado, están mostrando hoy en día un potencial inmenso dentro de las aulas de Educación Musical y, por otro, empiezan a delinear notables e interesantes aspectos de desarrollo futuro que hacen tan imprevisible como prometedora su configuración para los próximos años.

Los procesos sociales actuales han evidenciado un cambio en el modelo educativo que ha afectado sensiblemente a las metodologías de enseñanza musical. Dentro del contexto español, en el transcurso de las tres últimas décadas se ha pasado de la ausencia pertinaz de aulas específicas de música en los centros educativos a su aparición y florecimiento con una dotación característica (por lo general material derivado de la Orquesta Orff) la cual, finalmente, ha virado hacia las potencialidades TIC. En este sentido, la vertiente audiovisual ha ganado un imparable protagonismo, merced a su capacidad para reutilizar los recursos metodológicos y materiales preexistentes y a su economía de medios, ya que una simple pizarra digital o un ordenador conectado a un cañón permite un mínimo de utilización que reporta grandes beneficios en todos los ámbitos de la enseñanza de la música.

En consecuencia, el fenómeno del audiovisual en la Educación Musical puede ser analizado desde el propio desarrollo de materiales y recursos dentro de las aulas -a través del impulso que los docentes han ido implementando con su experimentación constante y continuao, de manera particular, desde el auge que la investigación en torno a la didáctica de la música inserta en el audiovisual ha mostrado en los últimos tiempos, generando una creciente bibliografía que deja patencia del interés y posibilidades que se le presuponen.

En referencia al primero de los ámbitos, es constatable que el avance tecnológico ha servido para configurar un campo de trabajo pedagógico tan enriquecedor para los docentes como motivador para los alumnos. Si, como atestiguan los pioneros del uso audiovisual en las aulas, los medios audiovisuales eran utilizados, en origen, como elemento de refuerzo en situaciones concretas que precisaban de un complemento alternativo a la enseñanza magistral, el desarrollo sobrevenido nos informa sobre la revolución que el audiovisual ha propiciado en el entorno de la Educación Musical. En este sentido, los modelos de aplicación son un ejemplo del modo en que 
los alumnos pueden interactuar con el compendio audiovisual y aprovechar sus posibilidades como marco de trabajo dentro de las aulas. Así, entre la gama de procedimientos hallamos experiencias que se sirven de la extrapolación de melodías venidas del audiovisual, de forma que discursos musicales con especial atractivo puedan ser extraídos de su origen para desarrollarse de manera prototípica, por ejemplo, a través de instrumentaciones o acompañamientos; desarrollos pedagógicos basados en el conocimiento musical a través del audiovisual, como puedan ser series de conciertos didácticos o biopics musicales, haciendo que el propio argumento del documento audiovisual con la adición de actividades aledañas suponga, en sí, un aporte significativo para el proceso educativo; filmaciones o elaboraciones de discursos audiovisuales, tales como los registros de actividades de aula o los propios musicogramas con movimiento, recurso en auge dadas las facilidades que los programas informáticos actuales proporcionan para la realización y el montaje; sonorizaciones, dentro de sus múltiples variedades, propiciando que el alumno se inmiscuya en el complejo audiovisual para realizar aportes, modificaciones o, simplemente, para aplicar alternativas al discurso sonoro.

Por otro lado, como fue apuntado, el empuje de la pedagogía con los medios audiovisuales en las aulas de música ha tenido un reflejo claro y sostenido en la literatura didáctico-musical de la última década. Aunque la legislación educativa pueda circunscribir de manera más directa la Educación Audiovisual a la materia hermana de la Plástica (omitiendo de manera lastimosa lo que debería ser la necesidad de un acercamiento directo desde la propia Educación Musical), son numerosos los investigadores que han hallado el modo de integrar dentro de los márgenes de los bloques de contenido existentes y las metodologías de referencia en nuestro contexto, un buen número de procedimientos de gran valor didáctico que han demostrado su eficacia como resortes de significación y aprendizaje en todos los ámbitos curriculares. La efervescencia de publicaciones en revistas y aportaciones en congresos dedicados a la Educación Musical han culminado en la tematización concreta de tesis doctorales que tienen como referencia todo tipo de elementos audiovisuales (cine, series, anuncios televisivos, videojuegos...) en su vinculación con la música dentro de las aulas.

Por consiguiente, gracias a las experiencias acumuladas en los últimos tiempos y a la teorización llevada a cabo, docentes e investigadores poseen un conjunto de referencias crecientes que pueden servir de asidero para delinear el futuro de una disciplina que cuanto más se indaga y desarrolla más invita a continuar sobre ella, comprobadas sus posibilidades y los inmensos beneficios reportados en nuestros alumnos, así como en la propia actualización metodológica de una Educación Musical que, como toda disciplina ligada íntimamente a los procesos culturales, requiere una actualización constante acorde con la evolución de la propia sociedad. 